\title{
SCHISTOSOMA MANSON!: INFECÇÃO EXPERIMENTAL DE CAMUNDONGOS ATRAVES DA ORELHA E QUANTIFICAÇÃO dO PARASITISMO NA PELE (1)
}

Silvia E. GEXKEN (2), Aparecida F. S. OLYVEXRA (3), Rodrigo CORREA-orivema (3)

\& Tomaz A. MOTA-SANTOS (3)

\section{R E S U M O}

No presente trabalho, desenvolveu-se método de infecção de camundongos através da orelha e de recuperação de esquistossômulos resultantes dessas in fecçōes. Cerca de $\mathbf{8 0 \%}$ das cercárias postas em contacto com orelhas de camundongos penetraram. Destas, $30 \%$ foram recuperadas como vermes adultos, do sistema porta. Da pele (das orelhas) as maiores recuperações de esquistossômulos ocorreram nos dois primeiros dias após a infecção. Os parasitas permaneceram nesse sítio por dois dias. No terceiro dia, os parasitas foram recuperados tanto da pele como dos pulmōes. A partir do $4 .^{\circ}$ dia, foi predominante a recuperação de esquistossômulos ao nível dos pulmōes. Do total de parasitas que potencialmente atingiriam o sistema porta, proporção elevada (73-80\%) pode ser recuperađa da pele, no segundo dia após a infecção, como esquistossômulos.

Revelando-se apropriadas ao acesso, à migração no hospedeiro e às técnicas de recuperação de parasitas, sugere-se que orelhas de camundongos podem ser utilizadas como sítio de infecção para estudos que visem a análise parasitológica dos eventos iniciais da infecção em animais normais ou imunes.

UNITERMOS: Esqustossomose experimental do camundongo; S. mansoni - In. festação experimental através da orelha; Recuperação de esquistossômulos.

\section{N T R O D U G A O}

Avaliação da imunidade de camundongos ao Schistosoma mansoni tem sido determinada comparando-se a recuperação de parasitas provenientes de uma infecção em animais já parasitados (infecção secundária) com a recuperação de parasitas de uma infecção provocada em animais normais (infecção primária). Com maior frequiência, infecçōes para avaliação do imunidade são feitas através da cauda 4,16 ou do abdomen $14,18,19,20$ e as recuperações dos parasitas delas resultantes efetuadas dos pulmões $5,4,14,18,22$ ou do sistema porta $4,16,19$.
Em 1980, SMITHERS \& GAMMAGE 19. após incubarem com colagenase fragmentos de pele parasitada, verificaram redução do número de esquistossômulos recuperados da pele do abdomen de camundongos imunes 48 horas após a infecção secundária. Manifestação tão precoce de resistência a reinfecção tornou relevante o estudo da imunidade adquirida nos períodos iniciais da infecção secundária e, em consequiência, tornou também necessário o desenvolvimento de metodologias de infecção experimental e de recuperação quantitativa de

(1) Pesquisa com auxilio financeiro do CNPq, PIDE (403809/82 - 403806/82) e FINEP (n.0 433)

(2) Departamento de Parasitologia, ICB/UFMG

(3) Departamento de Bioquímica-Imunologia, ICB/UFMG, Belo Horizonte, MG, Brasil

Correspondêneia: Silvia Elizabeth Gerken

Departamento de Parasitologia - ICB/UFMG

Caixa Postal 2486 - 30161 Belo Horizonte, MG, Brasil 
GERKEN, S. E.; OLIVEIRA, A. F. S.; CORREA-OLIVEIRA, R. \& MOTA.SANTOS, T. A. - Sehistosoma mansoni: infeoçä̀ experimental de camundongos através da orelha e quantificaçăo do parasitismo na pele, Rev. Inst. Med. trop. Sáe Prulo, 28:381-388, 1986 .

parasitas da pele, para facilitarem o estudo dos eventos que ocorram nesse local imediatamente após o hospedeiro ter sido exposto às formas infectantes.

Neste trabalho, foram investigados alguns aspectos da infecção experimental de camun. dongos normais através da orelha, assim como a quantificaçăo do parasitismo nesse sítio, com objetivo de desenvolver essas metodologias.

\section{MATERIAL E METODOS}

\section{Cercárias}

Cercárias do S. mansoni (cepa LE, Belo Horizonte, MG, Brasil) foram obtidas de Biomphalaria glabrata mantidos em laboratório e concentradas segundo técnica de GAZZINELLI et al. ${ }^{8}$.

\section{Infecção de camundongos}

Foram utilizados camundongos $\mathrm{C} 57 \mathrm{BL} / 10$ de nossa colônia, normais, machos, com 50-60 dias de idade no início dos experimentos.

A infecção dos camundongos se deu por exposição de uma das suas orelhas a um número conhecido de cercárias, segundo técnica de GERKEN et al. 9 , que é ilustrada nas Figuras 1 e 2 e sumariada em seguida. Preliminarmente, foram feitos numa tábua, orifícios com $1,3 \mathrm{~cm}$ de diametro em cada um dos quais foi afixado por pressão, um "batoque" (artefato de poliestireno com $1,5 \mathrm{~cm}$ de diåmetro e 1,0 $\mathrm{cm}$ de profundidade, em geral usado para tam. par garrafas; aqui, o "batoque" foi destinado a funcionar como reciplente ou "poço" para conter a suspensão cercariana). Camundongos, previamente anestesiados por aplicação por via intraperitoneal de $120 \mathrm{mg} / \mathrm{kg}$ de Diempax (Lafi - Usafarma, Săo Paulo) e, dez minutos após, com aplicação de $35 \mathrm{mg} / \mathrm{kg}$ de Nembutal (Abbott, São Paulo), eram presos na tábua acima descrita de modo que uma de suas orelhas ficasse imersa numa suspensão de 250-350 cercárias aplicadas a cada poço (cercárias aplicadas ou CA). Decorridos de 15 a 60 minutos de contacto com as cercárias, os camundongos eram removidos da tábua e transferidos para gaiolas, onde eram mantidos até o momento de recuperaçäo dos parasitas.

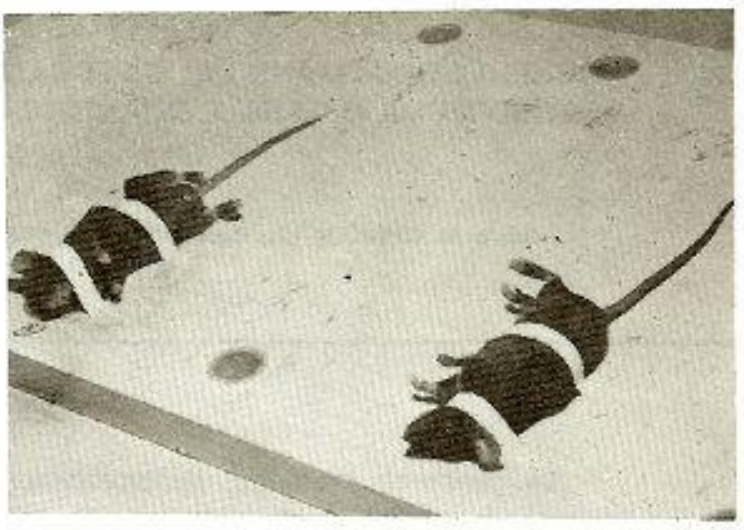

Fig. 1 - Infeccão de orelhas de camundongos por cercárias do S. mansoni

Orelhas de camundongos presas a uma tábua por meio de fitas de esparadrapo, permaneceram mergulhadas, durante 5 a 50 minutos, em recipiente de poliestireno contendo 250 a 350 cercárias.

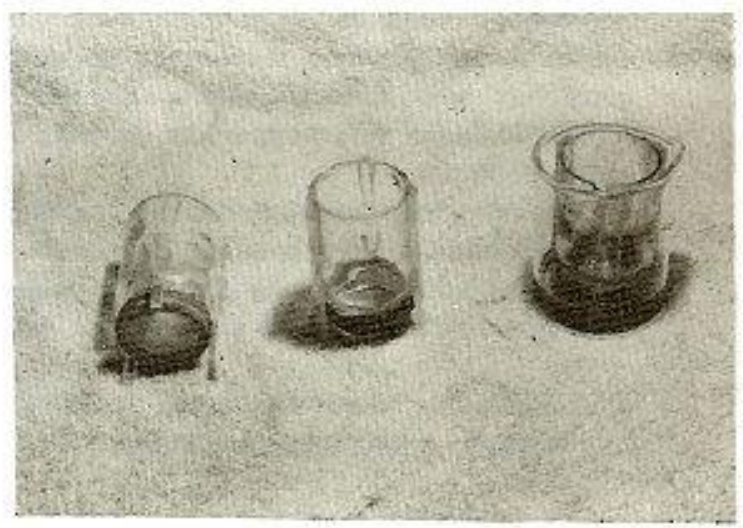

Fig. 2 - Recuperaçăo de esquistossómulos de fragementos de orelhas de camundongos

Fragmentos de orelhas infectadas de camundongos eram depositados sobre a tela de arame, em contacto com a soluçāo de incubaçāo, contida no béquer. Após quatro horas da incubaçäo a $37^{\circ} \mathrm{C}$, procedia-se a obtençăo dos es. quistossómulos, que migraram dos fragmentos para a solug̣ăo de incubaçăo.

Realizada a infecçäo, coletava-se o conteúdo de cada poço, para contagem dos corpos cercarianos e cercárias integras que, somados. correspondiam às cercárias que näo penetra vam (CNP). Procedia-se então ao cálculo das cercárias que penetraram (CP), que, expresso em porcentagem, era feito usando-se a seguinte formula:

$$
\mathrm{CP}(\%)=\frac{\mathrm{CA}-\mathrm{CNP}}{\mathrm{CA}} \times 100
$$


GERKEN, S. E.; OLIVEIRA, A. F. S.; CORREA-OLIVEIRA, R. \& MOTA-SAN'TOS, T. A. - Schistosoma mansoni: infecçāo experimental de camundongos através da orelha e quantificação do parasitismo na pele. Rev. Inst. Med. trop. São Paulo, 28:381-388, 1986.

\section{Recuperação dos parasitas}

As recuperações dos esquistossômulos das orelhas infectadas foram realizadas nos períodos de pós-infecção indicados em cada experimento, de acordo com a técnica anteriormente descrita 9, adaptada de técnicas de obtenção de esquistossômułos pulmonares ${ }^{3}$. A orelha infectada do camundongo mantido sob anestesia era removida cirurgicamente e transferida para suporte de máquina apropriada para obtenção de fragmentos com cerca de 300 micrômetros (The Mickle Laboratory Eng. Co., Surrey, Inglaterra). A fim de facilitar a obten. ção de fragmentos, cobria-se cada orelha com um pedaço de plástico fino (Zapp - Vulcan, São Paulo). Os fragmentos eram incubados a $37^{\circ} \mathrm{C}$, por quatro horas, em salina de Earle tamponada com Hepes $(20 \mathrm{mM})$ em pH 7.4, e ainda contendo: $0,5 \%$ de hidrolisado de lactoalbumina, uma unidade/ml de estreptomicina e uma unidade $/ \mathrm{ml}$ de penicilina (solução de incubação). Para a incubação, utilizava-se o dispositivo exposto na Figura 2. Ele consiste de um frasco de vidro, com ambas as ex. tremidades vazadas, estando uma delas recoberta por uma tela de arame (cujos orifícios tinham diâmetro de 200 micrômetros) e presa a suportes de plástico. Este dispositivo era colocado em um béquer de $50 \mathrm{ml}$ contendo cer- ca de $10 \mathrm{ml}$ da solução de incubação. Os parasitas migravam dos fragmentos de tecidos depositados na tela de arame para a solução de incubação, de onde eram reconhecidos e contados. Para isto, a solução de incubação era transferida para tubo de centrifuga, centrifugada e decantada. Ao sedimento, adicionavam-se duas gotas de solução $0,2 \%$ de vermelho neutro, que cora os esquistossômulos ${ }^{6}$. Para con. tagem, o sedimento era transferido para lâmina de plástico com fundo quadriculado e examinado ao microscópio de inversão (WILD M40, Suiça). Para efeito de comparação, parasitas eram também recuperados dos pulmões - por técnica de SHER et al, ${ }^{18}$, modificada por CORREA-OLIVEIRA et al. $\left.\right|^{3}$ - e do sistema porta, por perfusão, usando-se técnica de PELLEGRINO \& SIQUEIRA ${ }^{17}$.

\section{RESULTADOS}

Cerca de $80 \%$ das cercárias penetram na orelha de camundongos normais, quando postas em contacto com esse órgão por 45 minutos. Destas, $30 \%$ são recolhidas do sistema porta como vermes adultos, no $40^{\circ}$ dia de infecção (Tabela 1). Isto implica que a orelha de camundongo é um sítio que pode ser utilizado para provocar infecções experimentais viáveis com o $\mathbf{S}$. mansoni.

T A B E L A 1

Recuperação de vermes do sistema porta de camundongos normais infectados com o s. mansoni através da orelha

\begin{tabular}{|c|c|c|c|c|c|}
\hline \multirow{2}{*}{ Experimentos } & \multicolumn{3}{|c|}{ Cercárias } & \multirow{2}{*}{$\begin{array}{l}\text { Vermes recuperados } \\
\text { do sistems oprta (a) }\end{array}$} & \multirow{2}{*}{$\begin{array}{l}\% \\
(b)\end{array}$} \\
\hline & Aplicadas & Que penetraram (\%) & Restantes ( $\%)$ & & \\
\hline 1 & 250 & $185(74)$ & $65(26)$ & $54 \pm 19$ & 29 \\
\hline 2 & 270 & $200(74)$ & $70(26)$ & $63 \pm 16$ & 32 \\
\hline 3 & 250 & $210(84)$ & $40(16)$ & $46 \pm 13$ & 22 \\
\hline 4 & 250 & $218(87)$ & $32(13)$ & $78 \pm 19$ & 36 \\
\hline 5 & 260 & $214(82)$ & $46(18)$ & $59 \pm 25$ & 28 \\
\hline 6 & 250 & $195(78)$ & 55 (22) & $70 \pm 19$ & 36 \\
\hline 7 & 260 & $214(82)$ & $46(18)$ & $59 \pm 25$ & 28 \\
\hline
\end{tabular}

Orelhas de camundongos normais foram expostas a $250-270$ cerćárias por 50 minutos. No 40.0 dia após a infecção procedeu.se à recuperaça dos vermes do sistema porta.

(s) média \pm d.p.; $(n=7$ a 10$)$

(b) porcentagem de vermes recuperados em relaçāo so número de organismos que penetraram.

A Tabela 2 mostra que se recuperam esquistossômulos da pele incubando-se fragmentos do teciđo em soluçäo salina de Earle enriquecida com hidrolisado de lactoalbumina. Essa recuperação é todavia menor que a recuperaçăo de vermes obtida do sistema porta.
A Figura 3 mostra que as recuperaçōes de esquistossômulos de fragmentos da orelha são mais elevadas nos primeiro e segundo dias $(23 \%$ e $21 \%$, respectivamente), declinando a partir daí para apenas $1 \%$ no $5 .^{\circ}$ dia. Estudou-se 0 tempo em que os parasitas permanecem no si. 
GERKEN, S. E.; OLIVEIRA, A. F. S.; CORREA-OLIVEIRA, R. \& MOTA-SANTOS, T. A. - Schistosoma mansoni: infeç̧̄̄o experimental de camundongos através da orelha e quantificaçāo do parasitismo na pele. Rev. Inst. Med. trop. Săo Paulo, 28:381-388, 1986.

T A B E L A 2

Número de parasitos recuperados da pele e do sistema porta de camundongos normais

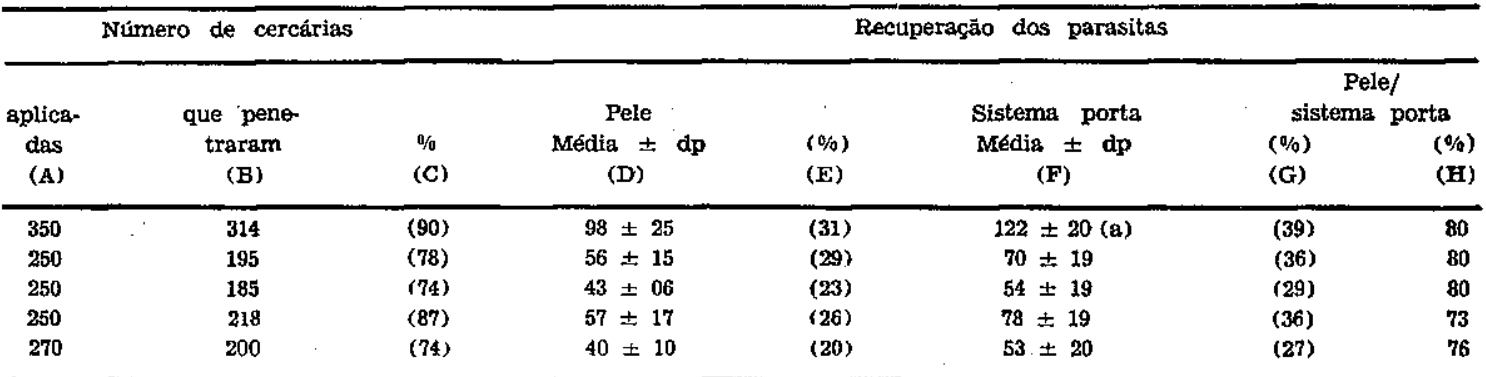

Orelhas de camundongos normais foram expostas a 250-350 cercárias (A) por 50 minutos. As diferenças entre as cercárias aplicadas e as restantes nos recipientes representam as que penetraram (B). A coluna $\mathbf{C}$ indica a porcetagem de parasitas que penetraram. Recuperação dos parasitas foram efetuadas de orelhas (D) e do sistema porta (F) no segundo e 40. dia, respectivamente. A coluna $H$ mostra a porcentagem de parasitas obtidos da pele om relagăo aos obtílos do sistema porta ( $\mathrm{n}=7$ a 9 ).

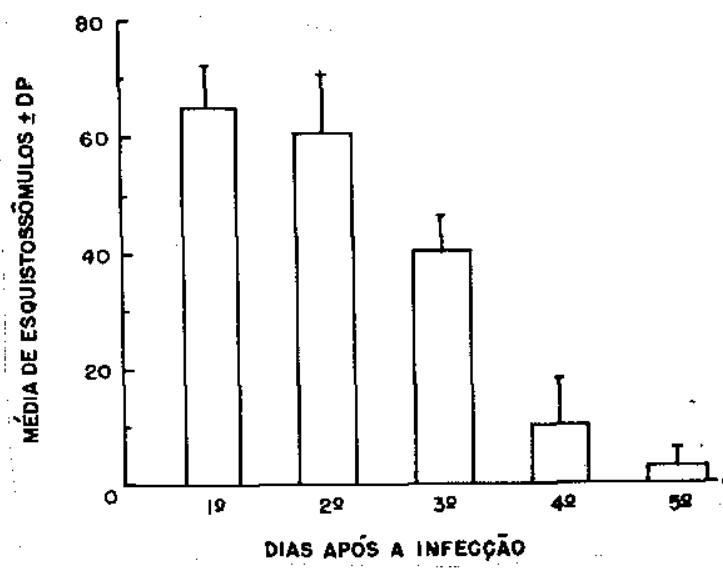

Fig. 3 - Recuperaçẫo de esquistossômulos de fragmentos de orelhas de camundongos normais, dias após a infecção. Orelhas de camundongos normais foram expostas a $280 \pm 18$ cercérias. A recuperaçāo âos esquistossómulos se deu pela incubaçăo em Elac, de fragmentos de orelhas coletadas em dias sucessivos após a infecção.

tio de penetraçäo. Para isto, camundongos foram infectados por uma de suas orelhas, que eram removidas em dias sucessivos após a infecção, até o quarto dia. Decorridos cinco dias da infecção, os camunđongos eram sacrificados e obtinham-se esquistossômulos dos pulmões. Como mostra a Figura 4, não foram recuperados parasitas dos pulmões dos animais cujas orelhas foram removidas até dois dias após a infecção; remoção a partir do terceiro dia não impediu a migração dos parasitas para os pulmões, que ja ocorreu quase totalmente no quarto dia da infecção. Disto se infere que os parasitas permanecem no local da infecção por pelo menos dois dias, após o que começam sua migraçăo para os pulmöes.

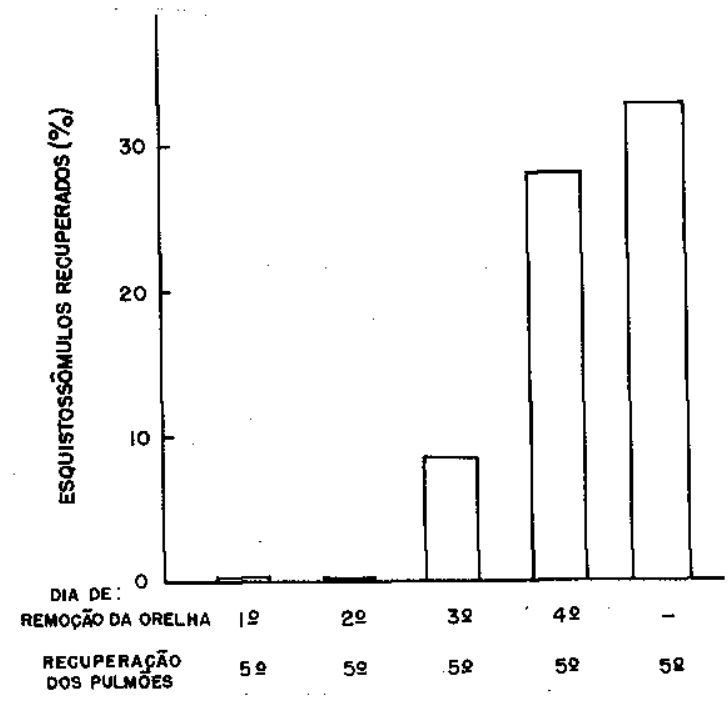

Fig. 4 - Recuperação de esquistossômulos dos pulmóes de camundongos infectados através da orelha, removida cirurgicamente em dias sucesstvos após a infecção

Orelhas de camundongos normais 1oram expostas a $250 \pm 15$ cercúrias. Nos dias indicados na Figura, as orelhas foram retiradas dos camundongos previamente anestesiados. Os esquistossômulos foram recuperados de fragmentos de pulmōes, incubados em Elac, no $5 .^{\circ}$ dla após a infecçăo $(n=7)$.

Fez-se tentativa de obter esquistossômulos da pele e dos pulmóes dos mesmos animais nos dias que se sucedem à infecção. A Figura 5 mostra que no primeiro e segundo dias re. cuperou-se esquistossômulos somente das orelhas, mas não dos pulmōes. A partir do quarto dia, é predominante o número de parasitas recuperados dos pulmöes. Os dados contidos na Tabela 3 referem-se a experimento no qual tentou-se padronizar o tempo de exposição a cercárias que favorece infecções mais elevadas. 
GERKEN, S. E; OLIVEIRA, A. F. S.; CORREA-OLIVEIRA, R. \& MOTA-SANTOS, T. A. - Schistosoma mansoni: infecçāo experimental de camundongos através da orelha e quantificaçăo do parasitismo na pele. Rev. Inst. Med. trop. São Paulo, 28:381-388, 1986.

Como pode ser visto nessa Tabela, infecções mais elevadas são obtidas a partir de $45 \mathrm{mi}$ nutos de contacto das orelhas com a suspensão cercariana.

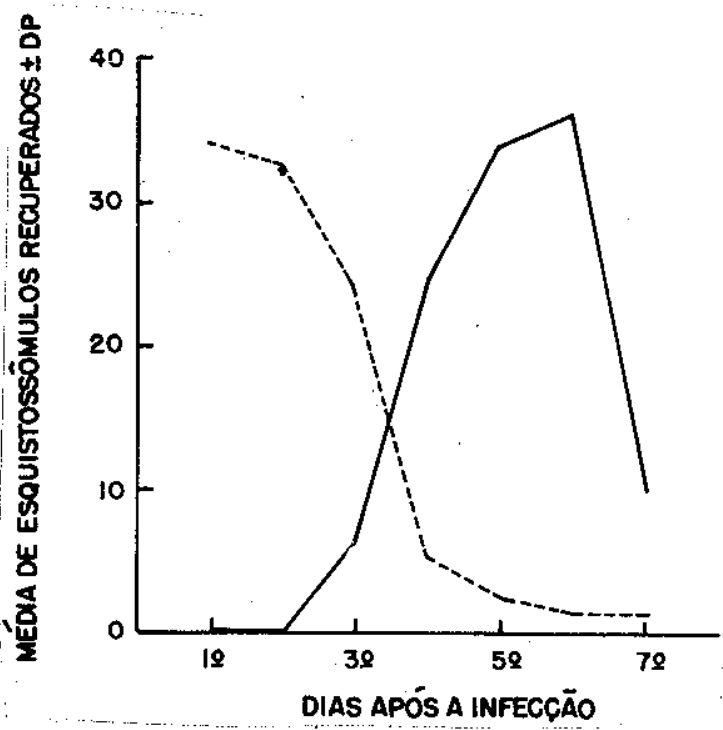

Fig. 5 - Recuperaçăo simultânea de esquistossômulos da pele e dos pulmőes de camundongos normais, dias após a infecçāo Orelhas de camundongos normais foram expostas a $258 \pm 18$ cercárias por 50 minutos. Nos dias que se seguiram os esquistossomulos foram recuperados de fragmentos de orelhas $(\ldots \ldots)$ e dos pulmōes (._. $)$ incubados em Flac $(\mathrm{n}=\mathrm{n})$.

\section{DISCUSSão}

No presente trabalho, buscou-se desenvolver um método simples de infectar camundongos através da pele, uma vez que ela é o sitio onde morre a maior parte das cercárias que penetram no organismo ${ }^{19}$. Por outro lado, é também importante desenvolver método de ob. tenção de esquistossômulos resultantes dessa infecção para que se possa analisar os eventos que ocorrem no periodo inicial da infecção pelo S. mansoni e que conduzem à redução local do parasitismo.

A infecção através da orelha dispensa algumas operações preparatórias do sítio de intecção, destacando-se a depilação que se faz com auxilio de lâminas apropriadas 20 . As operações adicionais podem também afetar com. ponentes da epiderme que se supõem possam estar envolvidos na resistência à penetração das cercárias 7. De fato, a infecção através da orelha demonstra ser menos eficiente que aquela que se faz através da pele depilada do abdomen; enquanto nesta penetram $90 \%$ das cercárias (dados não publicados) através da orelha penetram $80 \%$ (Tabelas 1 e 2 ).

E importante ressaltar que, em várias infecções experimentais, parte das cercárias não

T A B E L A 3

Esquistosso̊mulos recuperados da pele de camundongos normais submetidos a diferentes tempos de exposição a cercárias

\begin{tabular}{|c|c|c|c|c|c|}
\hline \multirow[b]{2}{*}{ Experimentos } & \multicolumn{3}{|c|}{ Cercárias } & \multirow{2}{*}{$\begin{array}{l}\text { Média de } \\
\text { esquistos- } \\
\text { sômulos re- } \\
\text { cuperados } \\
\pm d p\end{array}$} & \multirow[b]{2}{*}{$\%$} \\
\hline & Aplicadas & $\begin{array}{l}\text { Tempo de } \\
\text { exposigăo }\end{array}$ & $\begin{array}{c}\text { Que pene- } \\
\text { traram } \\
(\%)\end{array}$ & & \\
\hline \multirow[t]{4}{*}{1} & 220 & 15 & $165(75)$ & $33 \pm 06$ & $20(8)$ \\
\hline & & 30 & $189(86)$ & $36 \pm 10$ & 19 \\
\hline & & 45 & $187(85)$ & $43 \pm 05$ & 23 \\
\hline & & 60 & $175(80)$ & $49 \pm 09$ & 28 \\
\hline \multirow[t]{4}{*}{$\boldsymbol{z}$} & 260 & 15 & $182(70)$ & $42 \pm 13$ & 23 \\
\hline & & 30 & $152(60)$ & $41 \pm 18$ & 27 \\
\hline & & 45 & $158(61)$ & $41 \pm 10$ & 26 \\
\hline & & 60 & $186(72)$ & $52 \pm 14$ & 28 \\
\hline
\end{tabular}

(a) porcentagem de esquitossômulos recuperados em relacão ao número de cercárias que penetraram.

Orelhas de camundongos normais foram expostas por tempos variáveis, a $220 \pm 18$ e $260 \pm 29$ cercárias nos experimentos 1 e 2, respectivamente. Dois dias após os esquistossómulos foram recuperados de fragmentos da orelha incubados em Elac $(\mathbf{n}=\mathbf{7})$.

e capaz de penetrar na pele dos hospedeiros 12,19. Em nossos experimentos, 20\% das cercárias (10 a 31\%) não penetraram nas orelhas dos camundongos, mesmo após contacto por 50 minutos (Tabelas 1 e 2). Perda de in- fectividade poderia contribuir para esses resultados uma vez que cerca de 3 horas separam o início de eliminaçăo das cercárias pelos caramujos e a infecção das orelhas de camun. dongos. Desde que as cercárias apresentam, 
GERKEN, S. E.; OLIVEIRA, A. F. S.; CORREA.OLIVEIRA, R. \& MOTA.SANTOS, T. A. - Schistosoma mansoni: infecç̄̄o experimental de camundongos através da orelha e quantificação do parasitismo na pele. Rev. Inst. Med. trop. Säo Paulo, 28:381-388, 1986.

quando livres, extraordinária atividade e vi. vem às custas de suas próprias reservas de glicogênio ${ }^{1}$ é aceitável que esse período, separando a saída das larvas dos moluscos e seu con. tacto com o pele do hospedeiro, influencie em sua capacidade de penetraçăo. Por outro lado, a penetração das larvas deve ser dificultada pe. la barreira constituída pelas camadas superficiais da epiderme. Recentemente, FUKUYAMA \& cols. ${ }^{7}$ sugeriram que as células epidérmicas funcionariam não somente como um obstáculo mecânico mas, também, como uma barreira química à invasão cercariana, uma vez que purificaram dessas células uma substância que inibe 0 efeito das proteinases se. cretadas pelas glândulas pré-acetabulares.

A penetração das cercárias na pele é rápida e parece não se elevar quando hospedeiro e formas infectantes permanecem em contacto por mais que 45 minutos (Tabela 3). Dessa pe. netração $(74-90 \%)$ resulta uma infecção na qual o parasita atinge seu estádio final de de. senvolvimento e, como tal, é recuperado do sis. tema porta (22-39\%) em niveis comparáveis aos obtidos de animais infectados por outros sítios 12,14,19. Dessa maneira, a infecção através da orelha parece-nos ser, do ponto de vista parasitológico, método simples e confiável para produção de infecção experimental de camundongos.

Com relação à recuperação do S. mansoni, verificamos ser possivel obtenção de parasitas (Tabela 2, Figura 3) a partir da incubação de fragmentos de tecidos em um meio salino enriquecido com hidrolisado de lactoalbumina de maneira semelhante à usada para obtenção de esquistossômulos dos pulmões ${ }^{3}$ - o que representa modo mais simples que o método de SMITHERS \& GAMMAGE ${ }^{19}$.

No segundo dia após a infecção, foram obtidos da pele de camundongos infectados cerca de $26 \%$ das formas que penetraram (Figura 3 , Tabela 2). Essa proporção é um pouco menor que a obtida do sistema porta (33\%) a que seria explicável pela possível segmentação de parasitas durante a obtenção de fragmentos de tecidos, que perderiam assim sua capacidade migratória para a solução de incubação. Ainda assim, é possível verificar-se que apenas proporção variando entre 20 e $30 \%$ das larvas que penetraram pode ser recuperada da pele, logo após a infecção; a maior parte dos parasitas que penetram no hospedeiro não é recuperada nos animais infectados 12,19 nem visualizada no sítio da infecção por observação histologica 11. Esses resultados têm sido atribuidos à elevada mortalidade que poderia estar ocorrendo na pele, nas primeiras horas após a infecção 10,12,19, possivelmente devido à exaustão de suas reservas energéticas 2 ou por mecanismos "inespecíficos" de defesa do hospedeiro 9. Recentemente, porém, MANGOLD \& DEAN 19 responsabilizaram um sitio pós-pulmonar pela eliminação dos esquistossômulos nos hospedeiros normais.

$\mathrm{Na}$ pele da orelha, uma elevada porcenta. gem dos parasitas aí permanece por dois dias após a infecção (Figuras 3 e 4). Da pele do abdomen e da cauda os esquistossômulos começam a migrar para os pulmōes no segundo dia após a infecçăo. Aí se acumulam, alcançando quantidade mais elevada nos quinto e sexto dias e redução no número de parasitas nos dias subsequientes ${ }^{18}$. De maneira semelhante, nossos resultados mostram os esquistosômu. los iniciando a migração no segundo dia, chegan. do aos pulmōes no periodo compreendido entre os segundo e quinto dias e apresentando maior recuperação no sexto dia. A brusca re. dução que se observa no dia posterior traduz o trânsito de um grande número de esquistossômulos para o sistema porta (Figura 5).

A observação de que os parasitas permanecem no sítio da infecção por dois dias torna o periodo de zero a dois dias próprio para o estudo de eventos imunoparasitológicos que envolvam a relação parasito-hospedeiro nos momentos iniciais da infecçäo.

Nossos dados, como também estudos pré. vios 12,19 revelam que somente parte dos parasitas que penetram na pele de camundongos normais é recuperada como vermes adultos no sistema porta. Os resultados da Tabela 2 nos mostram que do total de parasitas que atinge o sistema porta, elevada proporção (73-80\%) é passivel de ser recuperada da pele como esquistossômulos. Por essa elevada proporção, é possível explorar-se o indice de recuperação de parasitas de orelhas como parâmetro parasitológico indicativo de efeitos de resistência ocorrendo tanto em animais normais quanto em animais imunes. 
GERKEN, S. E.; OLIVEIRA, A. F. S.; CORREA-OLIVEIRA, R. \& MOTA-SANTOS, T. A. - Schistosoma mansoni: infeçä̃o experimentạl de camundongos através da orelha e quantificaçăo do parasitismo na pele. Rev. Inst. Medi. trop. São Paulo, 28:381-388, 1986.

Os resultados sugerem que orelhas de camundongos sejam locais adequados ao acesso das cercárias no hospedeiro e à migração dos esquistọssômulos. Revelando-se, também. apropriadas a técnicas de recuperação de parasitas, poderão ser utilizadas como modelo experimental para estudos que envolvam imunidade cutânea de camundongos ao S. mansoni.

\section{AGRADEGIMENTOS}

Agradecemos a José de Souza Filho e a Ma. ria Ester Soares de Oliveira pela colaboração técnica. Agrädecemos também ao GIDE pelo fornecimentó das cercárias usadas neste trabalho.

\section{SUMMARY}

\section{Schistosoma mansoni: experimental infection of mice through the ear and estimation of skin parasitism.}

A method is presented to recover schistosomula from the skin of ear infected mice. About $80 \%$ of the cercariae applied to the ear were able to penetrate the mouse skin and $30 \%$ of them were recovered from the portal system as adult worms. The best recovery of larvae from the ear occurred in the two days that follow the penetration. From the $3^{\text {rd }}$ day on, parasites were recovered both from skin and lungs and on the 4th day they 'were already found mainly in the lungs. From 73 to $80 \%$ of the parasites eventually found in the portal system can be recovered as schistosomula from the skin on the $2^{\text {nd }}$ day of infection.

The use of the mouse ears is suggested for the parasitological analysis of the initial events of the S. mansoni infection both in normal and in immune animals, for they are very convenient to the cercarial access and to the use of methods of study of migration and recuperation of the larvae.

\section{REFERENCIAS BIBIIOGRAFICAS}

1. BRUCE, J. I.; WEISS, E.; STIREWAIT, M. A. \& IXNCICOME; D. R. - Schistosoma mansoni: glycogen content and utilization of glucose, pyruvate, glutamate and citric acid cyclo intermediates by cercariae and schistosomulum. Exp. Parasit., 26: 29-40, 1969.

2. CLEGG, J. A. \& SMITHERS, S. R. - Death of schistosome cercariae during penetration of the skin.
II - Penetration of mammalian skin by Schistosoma mansoni. Parasitology, 58: 111-128, 1968.

3. CORREA-OlIVEIRA, R.; MOTA-SANTOS, T. A. \& GAZZINELLI, G. - Schistosoma mansoni: "in vitro" and "in vivo" killing of antibody-coated schistosomula, Amer. J. trop. Med. Hyg., 31: 991-998, 1982.

4. DEAN, D. A.; CIOLI, D. \& BUKOWSKI, M. - Resistance induced by normal and irradiated Schistosoma mansoni: ability of various worm stages to serve as inducers and targets in mice. Amer. J. trop. Med. Hyg., 30: 1026-1032, 1981.

5. DEAN, D. A.; MINARD, P.; MURRELL, R. D. \& VANNIER, W. E. - Resistance of mice to secondary infection with Schistosoma mansoni. II - Evidence for a correlation between egg deposition and worm elimination. Amer. J. trop. Med. Hyg., 27: 957-965, 1978a.

6. DEAN, D. A.; MUNARD, P.; STIREWALT, M. A.; VANNIER, W. E. \& MURRELL, K. D. - Resistance of mice to secondary infetction with Schistosoma mansont. I - Comparison of bisexual and unisexual inicial in. fections. Amer. J. trop. Med. Hyg., 27: 951.956, $1978 \mathrm{~b}$.

7. FUKUYAMA, K.; TZENG, S.; MCKERROW, J. \& EPSTEIN, W. L. - The epidermal barrier to Schistosoma mansoni infection. Curr. Probl. Derm., 11: 185-193, 1983.

8. GAZZINELLI, G.; OLIVEIRA, C. G.; FIGUEIREDO, E. A.; PEREIRA, L. H.; COELHO, P. M. Z. \& PELLEGRINO, J. - Schistosoma mansoni; biochemical evi. dence for morphogenetic change from cercarla to schistosomule. Exp. Parasit., 34: 181-188, 1973.

9. GERKEN, S. E.; "MOTA-SANTOS, T. A.; CORREA. OLIVEIRA, R.; DIAS DA SILVA, W. \& GAZZINELLI. G. - The involvement of mast cell and vasoactive amines in the recovery of schistosomula of Schistosoma mansoni from rniouse skini. raz, J. med. biol. Res., 17: 301-307, 1984 .

10. GHANDOUR, A. M. \& WEBBE, G. - A study of the death of Schistosoma mansoni cercariae during penetration of mammalian host skin the influence of the ages of cercariae and of the host. Int. J. Parasit., 3: 794-784, 1973.

11. INCANI, R. N. \& MCLAREN, D. J. - Histopathological and ultrastructural studies of cutaneous reactions eli. cited in naive and chronically infected mice by in vading schistosomula of Schistosoma mansoni. Int: J. Parasit., 14: 259-276, 1984.

12. LAwSON, J. R. \& WILSON, R. Q. - The retationship between the age of Schistosoma mansoni cercariae and their ability to penetrate and infect mammalian host. Parasitology, 87: 481-492, 1983.

13. MANGOLD, B. L. \& DEAN, D. A. - Autoradiographic analysis of Schistosoma mansoni migration from skin to lungs in naive mice. Evidence that most attrition occurs after the skin phase. Amer. J. trop. Hyg., 32: 785-789, 1983. 
GERKEN, S. E.; OLIVEIRA, A. F. S.; CORREA-OLIVEIRA, R. \& MOTA.SANTOS, T. A. - Schistosoma mansoni: infecçăo experimental de camundongos através da orelha e quantificação do parasitismo na pele. Rev. Inst. Med. trop. São Paulo, 28:381-388, 1886.

14. MOTA-SANTOS, T. A.; TOLEDO, M. I.; CORREA, M. C. R.; CORREA-OLIVEIRA, R. \& GAZZINELI, G. - Schistosomiasis from $\mathbf{S}$. mansoni in mice: the relationship between acquired immunity and serum le. vels of lethal antibody. Paras. Immunol., 3: 319-327, 1981.

15. OLIVIER, L. 3. - Infectivity of Schistosoma mansoni cercariae. Amer. J. trop. Med, Hyg., 15: 882-885, 1966.

16. OLIVIFR, L. \& SCHNEIDFRMANN, M. - Acquired resistance to Schistosoma mansoni infection in laboratory animals. Amer. J. trop. Med. Hyg., 2: 289-306, 1953.

17. PELLEGRINo, J. \& SIQUEIRA, A. F. - Técnica de perfusão para colheita de Schistosoma mansoni em cobaias experimentalmente infestadas. Rev. bras. Malar., 8: 589-597, 1956.

18. SHER, A.; MACKENZIE, P. \& SMITHERS, S. R. Decreased recovery of invading parasites from the lungs as a parameter of acquired immunity of schis. tosomiasis in the mouse. J, Infect. Dis., 130: 626-633, 1974.
19. SMITHERS, S. R. \& GAMMAGE, K. - Recovery of Schistosoma mansonf from the skin, lungs and hepatic portal system of naive mice and mice previously exposed to S. mansoni: evidence for two phases of parasite attrition in immune mice. Parasitology, 80 289-300, 1980 .

20. SMITHERS, S. R. \& TERRY, R. J. - Acquired resistance to experimental infection of Schistosoma mansoni In the albino rat. Parasitology, 55: 711-717, 1965.

21. STIREWALT, M. A. \& HACKEY; J. R. - Penetration of host skin by cercariae of Schistosoma mansoni: I - Observed entry into skin of mouse, hamster, rat, monkey, and man. J. Parasit., 42: 565-580, 1956.

22. TAVARES, C. A. P.; SOARES, R. C.; COELHO, P M. Z. \& GAZZINEIII, -G. - Schistosoma mansoni: evidence for a role of serum factors in protecting artificially transformed schistosomula against antibody. mediated killing "in vitro". Parasitology, 74: 61-71, 1978a.

Recebido para publicação om 18/11/85. 